\title{
Malaysia backs 'gag' on haze scientists
}

[LONDON] The Malaysian government has justified a decision forbidding scientists at public institutions to talk to the press about the haze from Indonesian forest fires. It claims that a circular sent to vice-chancellors was designed to prevent scientists from publicizing the results of research before they had been peer-reviewed.

"That does not amount to a gagging order," says Zaini Ujang, a special adviser in the ministry of education. "Research on the haze is not comprehensive. There are many gaps, and we feel that it is not right for scientists to start talking to the press when many have only just begun to investigate this issue."

Parts of Malaysia remain covered by the haze, although pollution is slowly returning to 'normal levels'. Ujang's comments are widely seen as an effort to stem damage triggered by an interview by the Malaysian education minister, Najib Tun Razak, last week.

Scientists reacted with concern when the minister told reporters that the cabinet had barred scientists from making "negative statements" about sensitive issues such as the haze, on the grounds that such "speculative findings" were damaging the country's image abroad and harming tourism.

"Though some of them are experts in their respective fields, their statements on specific issues could give a worrying picture, and we want to avoid the alarmist attitude,"

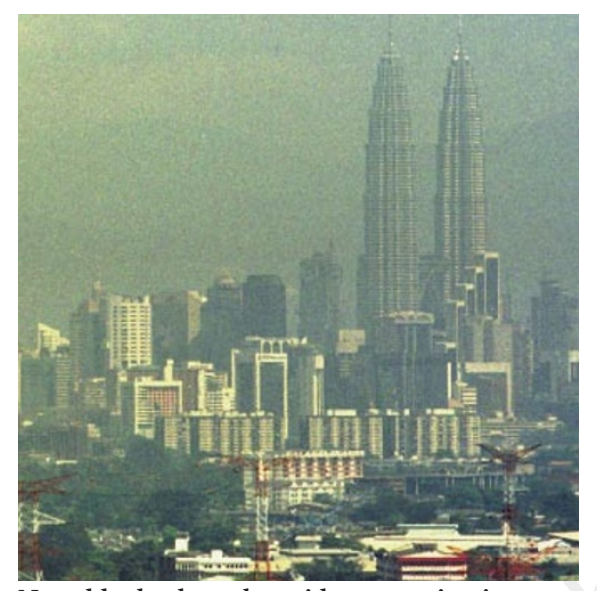

Not a blanket ban: the guidance to scientists applies only to the haze, says the government.

the minister told the Daily Star newspaper. Scientists should defer to "higher authorities" before making public statements.

The next day, Razak told reporters the gagging order applied to the haze only, and was not a "blanket ban" on all issues. "We are trying to prevent statements which are not supported by concrete scientific evidence and could easily damage the image of the country," he said.

Three Malaysian government departments - science, education and environment - recently set aside 4 million ringgit (US\$1.2 million) for research into the health effects of the haze. Ujang says that officials in the departments began to get annoyed when scientists on government research programmes made what he calls "conclusive statements" about the haze. One told a local newspaper that breathing the haze had the same effect as smoking 40 cigarettes a day.

"As funders of this research, they have a right to be annoyed," says Ujang. "When I was a research scientist with ICI in the UK, I had to brief the company before publishing in journals. Not all of my work was published. In fact, to this day some of my work has still not been allowed to be published."

As education minister, Razak lies third in the ruling party's pecking order, and is certain to challenge the deputy prime minister, Anwar Ibrahim, when the prime minister's job falls vacant. Some believe that Razak's comments will not only put back his promotion prospects but could also damage Malaysia's attempts to persuade scientists to communicate with the public.

"Scientists in Malaysia are notoriously wary of talking with the press or public," says Merryl Davies, editorial adviser to Malaysia's TV3 channel. "If I'd ring someone up for an interview they would say, 'have you spoken to my boss?' There's a strong culture of 'keep your head below the parapet and not be noticed'. The minister's comments will only encourage these habits."

EhsanMasood

\section{Largest-ever study contests radiation role in childhood cancers}

[LONDON] The theory that men who have been exposed to radiation father children with a higher-than-average risk of contracting childhood leukaemia/nonHodgkin's lymphoma (LNHL) received a new blow last week with the publication of the results of the largest study of its kind.

The survey used data from more than 100,000 workers occupationally exposed to radiation and confirmed a higher incidence of the disease among their children. But it did not establish a dose-response relationship. This suggests a factor other than radiation is the explanation.

Louise Parker, senior lecturer in epidemiology at the University of Newcastle upon Tyne, says the results, published in the British Medical Journal (7117, 1181-1188; 1997), "put another nail in the coffin" of the radiation theory, as did an earlier study published almost four years ago (see Nature 367,678 ; 1994).

"I think the idea that preconception irradiation of the father is a cause of childhood LNHL is now a dead duck," says Leo Kinlen, director of the Cancer Epidemiology Research Group at the University of Oxford, and one of the paper's authors.
Controversy about whether paternal irradiation places children at a higher risk of LNHL has raged since the publication of a paper in 1990 by the late Martin Gardner of the University of Southampton. Gardner found children of workers exposed to radiation were about eight times more likely to succumb to LNHL than the general population (see Nature 343,$676 ; 1990$ ).

The correlation of preconception irradiation with the increased risk of cancer in children subsequently became known as the 'Gardner hypothesis'. The finding surprised the scientific community, because similar conclusions could not be drawn from data from Hiroshima and Nagasaki.

Gerald Draper, principal author of last week's study, says that Gardner "did a good piece of epidemiology that generated a good hypothesis". But subsequent studies "have shown the hypothesis to be wrong".

Draper's study, explicitly set up to test the Gardner hypothesis, included all children up to 15 years of age born and diagnosed in Britain as having cancer between 1952 and 1986. The team matched the known childhood cases with individuals on the 120,000-strong British register of workers who are regularly monitored for radiation exposure.

The research team found that, overall, workers on the register were indeed more likely than the general population to have children who developed cancer; the average risk by age 15 in Britain is 6.5 per 10,000 children, and the authors estimate that this increases by 5.4 per 10,000 among children of workers on the register.

But they also found that there was no dose-response relationship. In fact there was a greater risk of childhood cancer among children of fathers on the register who had received a zero dose of radiation.

While appearing to overturn the Gardner hypothesis, the study has nevertheless made a significant contribution to the study of childhood cancers. One explanation, championed by Kinlen, is that infection is passed between people coming into an area and the previously isolated population.

The study is one of two recommended by the Committee on the Medical Aspects of Radiation in the Environment in the wake of Gardner's publication. The second, the Nuclear Industry Family Study, is expected to be published next year. Helen Gavaghan 